\title{
Balance control in individuals with developmental coordination disorder: A systematic review and meta- analysis
}

Citation for published version (APA):

Verbecque, E., Johnson, C., Rameckers, E., Thijs, A., van der Veer, I., Meyns, P., Smits-Engelsman, B., \& Klingels, K. (2021). Balance control in individuals with developmental coordination disorder: A systematic review and meta-analysis. Gait \& Posture, 83, 268-279.

https://doi.org/10.1016/j.gaitpost.2020.10.009

Document status and date:

Published: 01/01/2021

DOI:

10.1016/j.gaitpost.2020.10.009

Document Version:

Publisher's PDF, also known as Version of record

Document license:

Taverne

Please check the document version of this publication:

- A submitted manuscript is the version of the article upon submission and before peer-review. There can be important differences between the submitted version and the official published version of record.

People interested in the research are advised to contact the author for the final version of the publication, or visit the DOI to the publisher's website.

- The final author version and the galley proof are versions of the publication after peer review.

- The final published version features the final layout of the paper including the volume, issue and page numbers.

Link to publication

\footnotetext{
General rights rights.

- You may freely distribute the URL identifying the publication in the public portal. please follow below link for the End User Agreement:

www.umlib.nl/taverne-license

Take down policy

If you believe that this document breaches copyright please contact us at:

repository@maastrichtuniversity.nl

providing details and we will investigate your claim.
}

Copyright and moral rights for the publications made accessible in the public portal are retained by the authors and/or other copyright owners and it is a condition of accessing publications that users recognise and abide by the legal requirements associated with these

- Users may download and print one copy of any publication from the public portal for the purpose of private study or research.

- You may not further distribute the material or use it for any profit-making activity or commercial gain

If the publication is distributed under the terms of Article $25 \mathrm{fa}$ of the Dutch Copyright Act, indicated by the "Taverne" license above, 
Review

\title{
Balance control in individuals with developmental coordination disorder: A systematic review and meta-analysis
}

\author{
Evi Verbecque $^{\mathrm{a}, \mathrm{b}, *}$, Charlotte Johnson ${ }^{\mathrm{b}}$, Eugène Rameckers ${ }^{\mathrm{a}, \mathrm{c}, \mathrm{d}, \mathrm{e}}$, Angelina Thijs ${ }^{\mathrm{f}}$, \\ Ingrid van der Veer ${ }^{\mathrm{a}, \mathrm{e}}$, Pieter Meyns ${ }^{\mathrm{a}}$, Bouwien Smits-Engelsman ${ }^{\mathrm{g}}$, Katrijn Klingels ${ }^{\mathrm{a}}$ \\ ${ }^{a}$ Rehabilitation Research Centre (REVAL), Rehabilitation Sciences and Physiotherapy, Hasselt University, Agoralaan Building A, 3590, Diepenbeek, Belgium \\ ${ }^{\mathrm{b}}$ Department of Rehabilitation Sciences and Physiotherapy/Movant, Faculty of Medicine and Health Sciences, University of Antwerp, Belgium \\ ${ }^{\mathrm{c}}$ Department of Rehabilitation Medicine Maastricht University, Maastricht, the Netherlands \\ ${ }^{\mathrm{d}}$ Center of Expertise Adelante Rehabilitation, Valkenburg, the Netherlands \\ e AVANSplus, University for Professionals, Breda, the Netherlands \\ ${ }^{\mathrm{f}}$ Center of Development Advancement and Pediatric Neurorehabilitation of the Wildermeth Foundation, Biel/Bienne, Switzerland \\ ${ }^{g}$ Department of Health \& Rehabilitation Sciences, Faculty of Health Sciences, Division of Physiotherapy, University, Cape Town, South Africa
}

\section{A R T I C L E I N F O}

\section{Keywords:}

Postural balance

Balance control

Developmental coordination disorder

Motor skills disorders

\begin{abstract}
A B S T R A C T
Background: Although it is recognized that the majority of children with developmental coordination disorder (DCD) have balance deficits, comprehensive insights into which balance domains are affected, are still lacking in literature.

Research question: To what extent is balance control deficient in individuals with DCD compared to controls? Methods: Pubmed, Scopus and Web of Science were systematically searched. Risk of bias was assessed with the Scottish Intercollegiate Guidelines Network checklist for case-control studies. Mean and standard deviations characterizing balance control were extracted to calculate standardized mean differences (SMD) and pooled, if possible, using Review Manager.

Results: The results of 31 studies (1152 individuals with DCD, 1103 typically developing (TD) peers, mean age 10.4 years old) were extracted of which 17 were used for meta-analysis. The mean SMD for the balance subscale of the Movement Assessment Battery for Children was 1.63 (pooled $95 \% \mathrm{CI}=[1.30 ; 1.97]$ ), indicating children with DCD to perform significantly poorer than their TD peers. Force plate studies also revealed that children with DCD present with a larger sway path during bipedal stance with eyes closed (pooled mean SMD $=0.55 ; 95 \% \mathrm{CI}=$ $[0.32 ; 0.78])$. Children with DCD tend to have direction-specific limited stability limits and task-independent delayed onset of anticipatory postural adjustments.

Interpretation: Children with DCD perform poorer on different domains of balance compared to TD peers. Future research should focus on comprehensive balance assessment in these children, preferably using a longitudinal design.
\end{abstract}

\section{Introduction}

Worldwide, Developmental Coordination Disorder (DCD) accounts for 5-6\% of school-aged children [1,2]. These children experience difficulties in acquiring and performing a large set of motor skills, both gross and fine, in such a way that their motor performance is substantially below age-norms [1,2]. Importantly, these motor control difficulties cannot be explained by intellectual disability, visual impairment or an underlying neurological condition, such as cerebral palsy $[1,2]$. The presence of motor delay often persists into adolescence and interferes with participation in physical activities of daily life (ADL) [1, 3].

One of the main motor control problems in children with DCD is deficient balance control [4-6]. Essentially, controlling balance refers to the child's ability to keep or regain the centre of mass within the base of support during activities, ultimately to prevent a fall or a failure of results within an activity. However, consensus exists among researchers in this field that balance control comprises much more than that [7-9]. Children should be able to present different control strategies depending on the context at hand, e.g. reacting to an unexpected external

\footnotetext{
* Corresponding author at: Hasselt University, Agoralaan Building A, 3590 Diepenbeek, Belgium.

E-mail address: evi.verbecque@uhasselt.be (E. Verbecque).
} 
perturbation versus moving voluntarily which produces an expected internal perturbation that needs to be anticipated [7-9]. Movement strategies (ankle, hip or stepping strategy) should be flexibly applied in both static (stable base of support) and dynamic situations (moving base of support) [8]. Children also need to develop the ability to orient themselves in space through perception of gravity, surfaces, and verticality. Children will gradually learn to integrate this incoming sensory information to keep the body balanced [7-9]. Finally, the cognitive processes that allow learning and divided attention are crucial to remain balanced as well [7-9].

The most frequently used task to assess the prevalence of balance deficits in children with DCD is a timed one leg stance task (estimated at $60-87 \%$ of all cases) $[4-6,10]$. However, this task only measures a very limited aspect of activities or tasks that requires balance control. Unlike standing, the centre of mass during walking or moving between postures is not constantly within the same base of foot support; i.e. it moves synchronically with the changing base of support when moving from one foot or one posture to the next. Keeping balance during walking or changing posture (dynamic balance) requires complex control of a moving centre of mass. Apart from the type of balance task (static versus dynamic), the environment is also essential for balancing, e.g. walking in the dark (sensory perturbation) on uneven terrain (support surface perturbation) and complex activity demands (dual tasks) can hamper balancing $[7,11]$. Currently, the prevalence of deficient balance control in children with DCD might therefore be underestimated. This highlights that an integrated approach for exploring balance control in children with DCD is necessary.

To determine which aspects of balance control are affected directly relates to the conceptual framework used to define it. For example, a perceptual and ecological point of view on motor control has stimulated investigations into the nature of movements during postural and suprapostural tasks, i.e. tasks that require postural control, but have another behavioural goal such as fitting a block through a small opening while standing quietly [12]. This research has led to insights into the task-dependency of coordination dynamics and the development of new measures for postural control [11,12]. Although ecologically valid, such an approach does not allow for the identification of specific dysfunctional aspects of balance control. In 2009, Horak and colleagues integrated the different aspects of balance control into a conceptual framework consisting of five domains: limits of stability and verticality, anticipatory postural adjustments and transitions, reactive postural responses, sensory orientation, and stability in gait [8]. The domain limits of stability and verticality refers to the ability to move the body's centre of mass over its base of support and the extent to which this is possible (limits of stability) as well as the internal representation of gravitational upright (verticality). Anticipatory postural adjustments and transitions are active movements of the body's centre of mass in anticipation of a voluntary movement caused by feedforward projections. As a result of slips, trips and pushes, reactive postural responses are automatically elicited through short, medium and long proprioceptive feedback loops. Sensory orientation is established by integrating sensory information and using it for spatial orientation. The ability to adequately catch a falling body's centre of mass by a changing foot- or base of support is referred to as stability in gait. Importantly, these balance domains can be influenced by the presence of biomechanical constraints (e.g. muscle strength), i.e. a sixth domain musculoskeletal requisites for balance control. [8]

This conceptual framework has shown to be of use in the assessment of balance control in elderly people, stroke survivors, patients with Parkinson's disease and children with cerebral palsy, allowing researchers and clinicians to obtain a more in-depth understanding of balance deficits in the population of interest $[13,14]$. Such a comprehensive and targeted framework is particularly useful to set relevant and specific treatment goals [8]. By mapping the children with DCD's ability to control their balance in accordance with this framework, detailed insights can be gained into the extent to which balance deficits are present in these children.
Although it is recognized that the majority of children with DCD have balance deficits, comprehensive insights into which balance domains are affected, are still lacking in the literature. The aim of this systematic literature review and meta-analysis is therefore to explore balance deficits in individuals with DCD with respect to the different balance domains by comparing their performance to that of typically developing peers and/or groups of individuals with other types of neurodevelopmental disorder. This way, insights can be gained into whether all or specific balance domains are compromised and to what extent, optimising individualised treatment approaches.

\section{Methods}

This systematic review is written according to the Preferred Reporting Items for Systematic Reviews and Meta-Analyses (PRISMA) [15] and registered on PROSPERO (CRD42019123177).

\subsection{Search query and databases}

A systematic literature search was conducted in Pubmed, Web of Science and Scopus (last search update August 18th 2020). The search query comprised controlled terminology and free text terms relating to "developmental coordination disorder" and "balance". No date restrictions or filters were applied. The search queries are provided in detail in Appendix 1. After the selection process, the references of included studies were hand searched to identify potentially overlooked citations.

\subsection{Selection criteria}

Relevant studies were identified using predefined selection criteria according to the Population Intervention Comparison Outcome Study Design (PICOS) method:

1 Population: Individuals aged 5 years or older, diagnosed with (probable) DCD using the Diagnostic and Statistical Manual of Mental Disorders, $4^{\text {th }}$ edition (DSM-IV) or $-5^{\text {th }}$ edition (DSM-5), or the International Statistical Classification of Diseases and Related Health Problems, $10^{\text {th }}$ edition (ICD-10) criteria were of interest [1]. The specific criteria are presented in Appendix 2. Because of the large overlap between neurodevelopmental disorders, individuals with DCD with and without comorbidity were included. All studies were excluded in which not DCD but another neurodevelopmental disorder was the primary population of interest e.g. Autism spectrum disorder (ASD), Attention Deficit Hyperactivity Disorder (ADHD), specific language disorders (SLD), developmental dyslexia (DD) and other learning disorders.

2 Comparison: Performance on balance tests of individuals with DCD had to be compared to typically developing (TD) or healthy controls (children or healthy adults) or individuals with other neurodevelopmental disorders without DCD such as ASD, ADHD, dyslexia, specific language disorders, etcetera.

3 Outcome: Balance control had to be measured using a standardized assessment tool for which numeric data (mean and standard deviation/median and interquartile range) were reported. The tests had to be either specific balance tests (e.g. dynamic posturography) or balance subscales of a generic developmental motor scale (e.g. balance subscale of the Movement Assessment Battery for children, $2^{\text {nd }}$ edition - MABC-2). If a generic developmental motor scale was only used as a selection criterion (e.g. MABC Total Impairment Score and balance subscale score below the $5^{\text {th }}$ percentile) and not as an outcome measurement for balance, the study was excluded. This was done to avoid detection bias.

4 Study design and publication type: Original studies written in English, Dutch, French or German, with a case-control design were considered relevant. Conference proceedings/-reports, editorials, 
letters, case studies/-series, abstract only, (systematic) reviews and meta-analyses were excluded.

5 Risk of bias: Studies that received a rating of low methodological quality based on the Scottish Intercollegiate Guidelines Network (SIGN) [16] assessment were excluded.

The selection criteria were applied by two independent researchers (AT, EV) in the same sequence (population, comparison, outcome and study design) and in two phases (phase 1: title and abstract; phase 2: full text). After each phase, a consensus meeting was held to discuss the results of the article selection. In case of doubt or disagreement in phase 1 , articles were screened on full text. In phase 2 , a third reviewer's opinion (KK) was decisive. After phase 2, the references of the included studies were screened to ensure no relevant literature was missed. The selection process is presented in Appendix 3.

\subsection{Risk of bias assessment}

The SIGN is a validated checklist for case-control studies and was applied to assess risk of bias in individual studies $[16,17]$. The checklist assesses internal validity through selection and assessment bias, confounding factors and the use of statistical analyses and provides an overall quality assessment: high quality $(++)$ when the majority of criteria were met, implying little or no risk of bias and results unlikely to be changed by further research $(\geq 9 / 11$ criteria met), as acceptable quality $(+)$ when most criteria were met, implying methodological flaws with an associated risk of bias and conclusions may change in the light of further studies (6-8/11 criteria met) and as low quality( 0 ) when either most criteria were not met $(\leq 5 / 11)$ or significant flaws relating to key aspects of the study design were identified and conclusions likely to change in the light of further studies [16]. Studies were not included in

Table 1

Definitions of the domains of balance control and the applied methodology for their assessment.

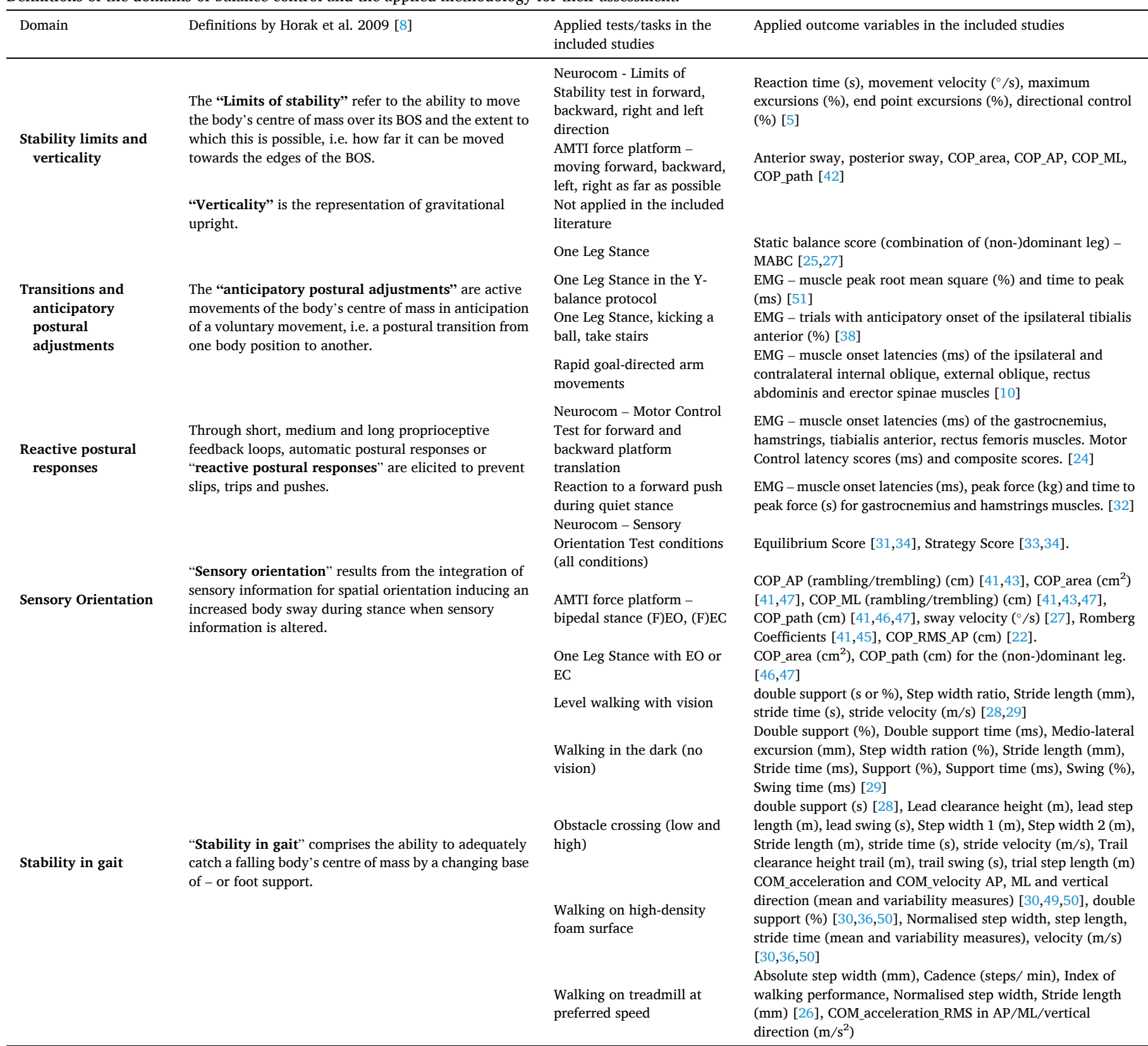

Legend: (F)EO: (Foam) Eyes Open; (F)EC: (Foam) Eyes Closed; BOS: Base of Support; COP: Centre of pressure; COM: Centre of Mass; AP: Anteroposterior; ML: mediolateral; MABC: movement Assessment Battery for Children; EMG: electromyography; RMS: Root mean square. 
the review as prescribed by the SIGN checklist guidelines in case of: 1 ) low quality or 2) if the study did not (a) adhere to clear definitions of the source population, (b) comment on how cases were selected, (c) address the influence of confounding factors or (d) provide a statement on psychometrics of the outcome measures or (e) base its main conclusions on primary outcomes [16].

Two independent researchers (CJ, EV) assessed risk of bias and discussed the results in a consensus meeting.

\subsection{Data-extraction, -synthesis -analysis}

After applying the selection criteria and risk of bias assessment, specific data to characterize the study populations, the applied outcome to assess balance control and their results were extracted. First, general population characteristics (number of participants per group, age range, sex distribution, mean values and standard deviation (SD) for age, height, weight and body mass index (BMI)) and specific characteristics for the patient groups (applied criteria for assigning diagnosis, presence of comorbidities) were mapped.

Secondly, numeric values (mean and $\mathrm{SD} /$ median and interquartile range (IQR)) for each outcome variable were extracted. Data obtained with a balance subscale of a generic motor scale were grouped and analysed, e.g. the MABC(-2). When data were derived from specific balance tests, e.g. the sensory organization test, the data were grouped and categorized according to five domains investigating balance control based upon the type of balance task or perturbation under investigation [8]: 1) Stability limits and verticality, 2) Transitions and anticipatory postural adjustments, 3) Reactive balance, 4) Sensory orientation and 5) Stability in gait. Table 1 provides an overview of the tests and their classification according to the balance domains. The domain mapping the biomechanical constraints, such as muscle strength and alignment, was not investigated. Although relevant for this group, this aspect of functioning was beyond the scope of this paper.

For all outcome measures, a standardized mean difference (SMD) was calculated using Hedges' g (SMD $=\frac{\left.\bar{X}_{\text {DCD }}-\bar{X}_{\text {CONTROLS }}\right)}{S D_{\text {pooled }}}$ [ [18]. Median values were assumed to equate the mean and the IQR was converted to standard deviations (IQRx0.75), using Hillier and Inglis-Jassiem's formula [19]. The SMD values were considered to represent a significant difference if the $95 \%$ confidence interval did not include zero [18]. The magnitude of the SMD can be interpreted as follows: small (SMD $\leq 0.2$ ), medium $(0.2<$ SMD $<0.8)$ or large (SMD $\geq 0.8)$ [18]. If at least two identical outcome variables (e.g. equilibrium score) of the same task (e. g. standing on a moving platform with eyes closed) were available, the numeric data were entered in Review Manager (RevMan 5) to present the individual and the subtotals of the SMD (graphically). The SMD subtotals were estimated with a random effects model. The $\mathrm{I}^{2}$ statistic describes the percentage of variation across studies that is due to heterogeneity rather than chance [20]. Higher $\mathrm{I}^{2}$ values indicate more heterogeneity among individual studies [20].

If multiple publications of the same research group were included, authors were contacted to establish whether the same sample was reported. When confirmed by the authors this was reported, avoiding reporting of duplicate results.

\section{Results}

\subsection{Search results}

The search query resulted in 481 unique hits, of which 65 were screened on full text. Finally, 31 studies met all selection criteria [5,10, 21-51] of which data were extracted. Most studies were excluded in phase $2(n=18)$ because they did not fulfil the criteria of the outcome of interest, 10 of which did not report numeric data representing balance control [52-61]. Three studies were excluded because of low methodological quality $[39,40,62]$. The data extracted from 17 studies $[10,21$,
23-25,31-35,37,41,42,45-48] could be pooled for meta-analyses, because they reported identical outcome variables for the same task. The selection process' flowchart is shown in Appendix 3.

\subsection{Risk of bias in individual studies}

Table 2 provides an overview of the risk of bias assessment. One study was of high quality [24], 30 studies had acceptable quality [5,10, 21-23,25-38,41-51] and three studies were of low quality and had to be rejected $[39,40,62]$. Of the studies of acceptable to high quality, twenty included studies $(64.5 \%)$ did not report the percentage of recruited children to actually participate in each study group [5,10,21,25,28,30, 26-38,42-44,48-50], twenty-five included studies (80.6\%) did not report confidence intervals $[5,10,21-23,25-31,34,36,26-38,41-47,49$, 50] and none of the studies transparently reported whether they had taken measures to prevent knowledge of the primary exposure influencing case ascertainment (risk for detection bias, nor compared the participants with the non-participants (risk for selection bias).

\subsection{Population characteristics}

All included studies compared balance in individuals with DCD to TD peers. Across the 31 included studies, balance control was assessed in a total of 1152 individuals with DCD (819 males, mean age 10.4 (5.0) years old) and 1103 individuals with TD (733 males, mean age 10.4 (5.2) years old). Thirty studies reported results on children with(out) DCD [5,10,21-29,31-38,41-51] between age 4 [25] and age 17 [36,49, 50]. Three studies reported on adults with(out) DCD [30,36,49]. Two studies reported data on the same sample [28,29]. Table 3 provides a description of the samples with respect to sex distribution, age, height, weight and BMI.

The included studies either reported children with a previously confirmed diagnosis of DCD [5,25,27-29,31-35,38,43,44,48], or children who met the diagnostic criteria of the DSM-IV [37,41,42], the DSM-5 [30,36,49,50] or the ICD-10 [23,45-47]. In two studies children were selected by the physical therapists or physical therapy departments where they received treatment $[10,26]$ making it assumable that these children received a diagnosis at some point. Specifics on the presence of a confirmed diagnosis and the degree to which the diagnostic criteria were met in the included studies are shown in Appendix 2.

\subsection{Performance on balance subscales of generic motor scales}

Nine studies reported on the balance subscale score of the MABC [10, $21,23-25,32,35,37,42]$, two on the balance subscale score of the MABC-2 $[31,48]$ and one study on the running speed and agility part of the Bruininks-Oseretsky Test for Motor proficiency (BOT-MP) [21]. Two studies were not considered for data-extraction, because the MABC data were part of the selection criteria, i.e. poor motor and balance performance $[27,45]$. For the MABC and MABC-2 balance subscale sufficient data were available to be pooled and analysed.

The overall mean SMD for the MABC balance subscale totalled 1.63 (pooled $95 \% \mathrm{CI}=[1.30 ; 1.97]$ ) for a total of 1004 participants, indicating a large difference with significantly poorer balance in the DCD group, but with a large amount of heterogeneity $\left(\mathrm{I}^{2}=79 \%\right)$ among the included studies (Fig. 1).

For the MABC-2 balance subscale the overall mean SMD was -0.95 (pooled $95 \% \mathrm{CI}=[-1.52 ;-0.39]$ ) accounting for 211 participants. This indicates again, a significant, large difference between groups in favour of the TD children, but also very heterogeneous results among the studies $\left(\mathrm{I}^{2}=70 \%\right)$.

In both cases, this suggests that between studies, children with DCD perform differently on the same balance tasks compared to their TD peers, indicating subclassification is needed.

Running speed and agility (BOT-MP subscale) was significantly poorer in children with DCD compared to TD peers (SMD =-1.44, $95 \%$ 
Table 2

Risk of bias assessment of individual studies - consensus scores.

\begin{tabular}{|c|c|c|c|c|c|c|c|c|c|c|c|c|}
\hline Authors & 1.1 & 1.2 & 1.3 & 1.4 & 1.5 & 1.6 & 1.7 & 1.8 & 1.9 & 1.10 & 1.11 & 2.1 \\
\hline Asonitou et al. 2012 & + & + & + & NR & - & + & + & ? & + & + & - & A \\
\hline Chen et al. 2012 & + & + & + & DCD: $15 \%$, TDC: $15 \%$ & - & + & + & $?$ & + & + & - & A \\
\hline Chen et al. 2016 & + & + & + & DCD: 5\%, TDC: $5 \%$ & - & + & + & $?$ & + & + & - & A \\
\hline Cheng et al. 2018 & + & + & + & DCD: $44 \%$, TDC: $36 \%$ & - & + & + & $?$ & + & + & + & $\mathrm{H}$ \\
\hline Cherng et al. 2007 & + & + & + & NR & - & + & + & $?$ & + & + & - & A \\
\hline Deconinck et al. 2006A & + & + & $?$ & DCD: NR, TDC: $4 \%$ & - & + & $?$ & ? & + & + & - & A \\
\hline Deconinck et al. 2006B & + & + & - & DCD: NR, TDC: $3 \%$ & - & + & + & - & + & + & - & A \\
\hline Deconinck et al. 2008 & + & + & $?$ & DCD: NR, TDC: $3 \%$ & - & + & + & $?$ & + & + & - & A \\
\hline Deconinck et al. 2010 & + & + & $?$ & NR & - & + & + & $?$ & + & + & - & A \\
\hline Du et al. 2015 & + & + & + & NR & - & + & + & ? & + & + & - & $\mathrm{A}$ \\
\hline Fong et al. 2011 & + & + & + & NR & - & + & + & ? & + & + & - & A \\
\hline Fong et al. 2012 & + & + & + & NR & - & + & + & ? & + & + & - & A \\
\hline Fong et al. 2013 & + & + & + & NR & - & + & + & $?$ & + & + & + & A \\
\hline Fong et al. 2015 & + & + & + & NR & - & + & + & ? & + & + & + & A \\
\hline Fong et al. 2016A & + & + & + & NR & - & + & + & ? & + & + & + & A \\
\hline Fong et al. 2016B & + & + & + & NR & - & + & + & $?$ & + & + & - & A \\
\hline Ganapathy \& Monisha 2019 & + & + & + & DCD: $20 \%$, TDC: $20 \%$ & - & $?$ & $?$ & $?$ & $?$ & + & - & $\mathrm{R}$ \\
\hline Gentle et al. 2016 & + & + & - & NR & - & + & + & $?$ & + & + & - & A \\
\hline Grove \& Lazarus 2007 & + & + & + & NR & - & + & + & $?$ & + & + & - & A \\
\hline Johnston et al. 2012 & + & + & + & NR & - & + & + & ? & + & + & - & A \\
\hline Kane \& Barden 2012 & + & - & - & NR & - & + & + & $?$ & + & + & - & $\mathrm{R}$ \\
\hline Kane \& Barden 2014 & + & $?$ & + & NR & - & + & + & ? & + & + & - & A \\
\hline Miller et al. 2018 & + & - & + & NR & - & + & - & $?$ & + & + & - & $\mathrm{R}$ \\
\hline Przysucha \& Taylor 2004 & + & + & + & DCD: $38 \%$, TDC: $38 \%$ & - & + & + & $?$ & + & + & - & A \\
\hline Przysucha et al. 2008 & + & + & + & NR & - & + & + & ? & + & + & - & A \\
\hline Speedtsberg et al. 2017 & + & $?$ & + & NR & - & + & + & ? & + & + & - & A \\
\hline Speedtsberg et al. 2018 & + & $?$ & + & NR & - & + & + & $?$ & + & + & - & A \\
\hline Tsai \& Wu 2008 & + & + & + & DCD: $83 \%$, TDC: $10 \%$ & - & + & + & $?$ & + & + & - & $\mathrm{A}$ \\
\hline Tsai et al. 2008 & + & + & + & DCD: $29 \%$, TDC: $33 \%$ & - & + & + & - & + & + & - & A \\
\hline Tsai et al. 2009 & + & + & + & DCD: $67 \%$, TDC: $10 \%$ & - & + & + & - & + & - & - & A \\
\hline Tsang et al. 2012 & + & + & + & $\mathrm{NR}$ & - & + & + & $?$ & + & + & + & $\mathrm{A}$ \\
\hline Wilmut et al. 2016 & + & $?$ & + & NR & - & + & + & ? & + & + & - & A \\
\hline Wilmut \& Barnett 2017 & + & $?$ & + & NR & - & + & + & ? & + & + & - & A \\
\hline Yam \& Fong 2018 & + & + & + & DCD: $24 \%$, TDC: $26 \%$ & - & + & + & $?$ & + & $?$ & + & A \\
\hline
\end{tabular}

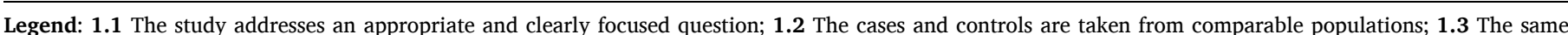

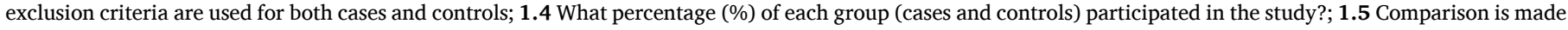

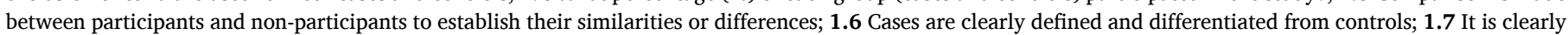

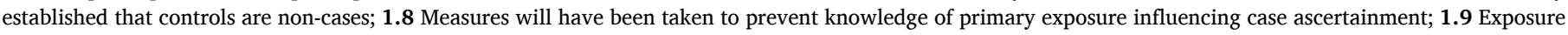

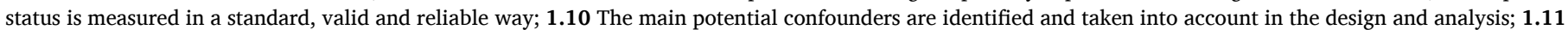

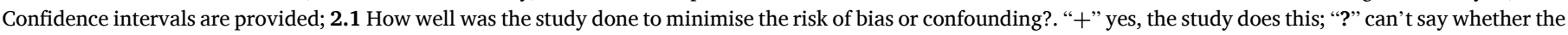

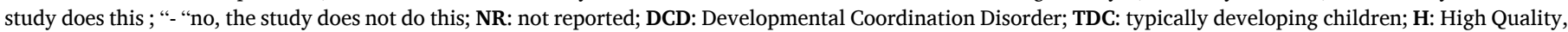
A: Acceptable quality; R: Reject.

$\mathrm{CI}=[-1.87 ;-1.02][21]$

\subsection{Performance on specific balance tests}

In 26 studies specific balance tests were used [5,10,22,24-34,36-38, 41-47,49-51]. Table 1 depicts the investigated domains of balance control and the corresponding tests and outcome variables.

\subsubsection{Functional stability limits and verticality}

Two studies reported on the functional limits of stability during bipedal stance [5,42], both using a different method (Table 1). Overall, children with DCD performed similarly to their controls (Appendix 4), except when they had to move towards their backward limits of stability [5]. None of the included studies reported on verticality.

\subsubsection{Transitions and anticipatory postural control}

Tasks in this domain comprised one leg stance [25,27,38,51], kicking a ball [38], taking the stairs [38] and making rapid goal-directed arm movements [10], which were assessed in five studies. Table 1 depicts the applied outcome measures. None of the available data could be pooled because of differences in applied tasks or outcome measures (Appendix 5). When addressing anticipatory control, postural muscle activation prior to the voluntary movement is of interest. Three studies applied electromyography [10,38,51], revealing a trend of deficits in children with DCD during limb movements in the anterior direction.
Compared to their TD peers, children with DCD present with slower contractions of the abdominal muscles and faster contractions of the erector spinae during fast arm movements [10], fewer trials comprising preparatory contractions of the tibialis anterior muscle when standing on one leg, kicking a ball and taking stairs [38] and shorter times to the peak contractions of gastrocnemius, tibialis anterior, hamstrings and rectus femoris during the Y-balance test in the anterior direction [51].

Timed one leg stance (item on the MABC) induced large differences when expressed as a standard score [25] in favour of TD children, whereas this is not the case for performance expressed in seconds [27].

\subsubsection{Reactive postural control}

In two studies reactive control mechanisms were assessed [24,32]. For this purpose, three different types of tests were applied, summarized in Table 1: the motor control test (neurocom) [24] and by giving the child a push forward when standing quietly [32]. Both methods elicit a similar muscular reaction to maintain the upright position and prevent a fall. As shown in Appendix 6, the results are conflicting: in response to a push, the contractions of hamstring and gastrocnemius were significantly later in children with DCD compared to TD peers, which was not the case when the platform moved unpredictably in the backward direction [24].

\subsubsection{Sensory orientation}

Sensory orientation was assessed in 11 studies, eight of which data 
Table 3

General description of the samples included in the individual studies.

\begin{tabular}{|c|c|c|c|c|c|c|c|c|c|c|c|c|c|c|c|c|c|c|c|c|c|}
\hline & \multicolumn{10}{|c|}{ Individuals with DCD } & \multicolumn{11}{|c|}{ Control groups } \\
\hline & \multirow{2}{*}{ Total (N) } & \multirow{2}{*}{ Boys (\%) } & \multicolumn{2}{|c|}{ Age (years) } & \multicolumn{2}{|l|}{$\begin{array}{l}\text { Height } \\
(\mathrm{cm})\end{array}$} & \multicolumn{2}{|c|}{ Weight (kg) } & \multicolumn{2}{|c|}{$\begin{array}{l}\text { BMI (kg/ } \\
\left.\mathrm{m}^{2}\right)\end{array}$} & \multirow{2}{*}{ Total (N) } & \multirow{2}{*}{ Boys (\%) } & \multirow[b]{2}{*}{ Group } & \multicolumn{2}{|c|}{ Age (years) } & \multicolumn{2}{|c|}{ Height $(\mathrm{cm})$} & \multicolumn{2}{|c|}{ Weight (kg) } & \multicolumn{2}{|c|}{$\begin{array}{l}\text { BMI (kg/ } \\
\text { m²) }^{2}\end{array}$} \\
\hline & & & mean & $S D$ & mean & $S D$ & mean & $S D$ & mean & $S D$ & & & & mean & $S D$ & mean & $S D$ & mean & $S D$ & mean & $S D$ \\
\hline Asonitou et al. 2012 [21] & 54 & 66.6 & 5.5 & 0.2 & & & & & & & 54 & 68.5 & $\mathrm{TD}$ & 5.6 & 0.2 & & & & & & \\
\hline Chen \& Tsai 2016 [22] & 30 & 60.0 & 11.87 & 0.5 & 147.21 & 8.82 & 49.0 & 9.5 & & & 30 & 46.7 & TD & 11.7 & 0.5 & 148.29 & 9.33 & 46.8 & 8.1 & & \\
\hline Chen et al. 2012 [23] & 38 & 55.3 & 9.4 & 0.5 & 139.11 & 6.66 & 37.9 & 11.3 & & & 38 & 55.3 & TD & 9.2 & 0.4 & 140.11 & 6.40 & 38.1 & 9.3 & & \\
\hline Cheng et al. 2018 [24] & 120 & 82.5 & 7.4 & 1.3 & 124.16 & 8.94 & 26.1 & 7.2 & 16.7 & 2.7 & 100 & 79.0 & TD & 6.7 & 1.1 & 120.39 & 8.54 & 23.3 & 5.9 & 15.9 & 2.3 \\
\hline Cherng et al. 2007 [25] & 20 & 80.0 & 5.5 & 0.9 & 113.20 & 7.30 & 21.5 & 4.5 & & & 20 & 80.0 & TD & 5.4 & 0.9 & 112.20 & 6.50 & 20.3 & 3.1 & & \\
\hline $\begin{array}{l}\text { Deconinck et al. 2006A [29]* } \\
\text { Deconinck et al. 2010 [28]* }\end{array}$ & 12 & 83.3 & 7.8 & 0.5 & 126.80 & 4.93 & 25.6 & 4.4 & & & 12 & 83.3 & TD & 7.7 & 0.6 & 127.50 & 6.13 & 25.6 & 3.4 & & \\
\hline Deconinck et al. 2006B [26] & 10 & 90.0 & 7.4 & 0.9 & 128.00 & 7.00 & 25.3 & 4.1 & & & 10 & 90.0 & TD & 7.5 & 0.85 & 131.00 & 5.10 & 28.0 & 4.4 & & \\
\hline Deconinck et al. 2008 [27] & 10 & 100.0 & 7.7 & 0.8 & 129.00 & 7.00 & 25.7 & 4.1 & & & 10 & 100.0 & TD & 7.6 & 0.9 & 132.00 & 4.00 & 28.5 & 4.6 & & \\
\hline Du et al. 2015 [30] & 15 & 60.0 & 25.3 & & & & & & & & 15 & 60.0 & TD & 25.4 & & & & & & & \\
\hline Fong et al. 2011 [31] & 81 & 77.7 & 8.1 & 1.5 & 130.53 & 11.87 & 33.1 & 11.6 & 18.9 & 3.7 & 67 & 71.6 & TD & 8.3 & 1.6 & 129.87 & 10.41 & 30.3 & 8.7 & 17.65 & 3.0 \\
\hline Fong et al. 2012 [34] & 22 & 72.7 & 7.5 & 1.4 & 124.80 & 10.40 & 27.4 & 8.4 & & & 19 & 68.4 & $\mathrm{TD}$ & 6.9 & 1.1 & 121.30 & 11.90 & 29.3 & 12.6 & & \\
\hline Fong et al. 2013 [33] & 58 & 84.5 & 7.6 & 1.2 & 126.60 & 10.20 & 27.8 & 8.5 & 16.9 & 2.7 & 46 & 73.9 & $\mathrm{TD}$ & 8.0 & 1.8 & 128.40 & 14.70 & 30.0 & 7.7 & 18.1 & 3.6 \\
\hline Fong et al. 2015 [32] & 130 & 68.5 & 7.7 & 1.4 & 123.50 & 10.60 & 25.2 & 7.9 & 16.1 & 2.5 & 117 & 63.2 & TD & 7.4 & 1.3 & 123.40 & 9.50 & 24.5 & 6.4 & 15.7 & 3.2 \\
\hline Fong et al. 2016A [35] & 86 & 75.6 & 7.9 & 1.7 & 125.00 & 11.50 & 26.6 & 8.8 & 16.6 & 2.7 & 99 & 74.7 & TD & 7.4 & 1.6 & 122.60 & 10.30 & 24.0 & 6.4 & 15.6 & 3.2 \\
\hline \multirow[t]{2}{*}{ Fong et al. 2016B [5] } & 30 & 76.7 & 7.7 & 1.5 & 123.70 & 11.50 & 26.0 & 9.2 & 16.5 & 2.8 & 20 & 55.0 & TD & 7.9 & 1.6 & 125.80 & 8.50 & 24.0 & 4.5 & 15.2 & 2.4 \\
\hline & 12 & 83.3 & 10.3 & 1.3 & & & & & & & 12 & 83.3 & TD & 10.3 & 1.3 & & & & & & \\
\hline \multirow[t]{2}{*}{ Gentle et al. 2016 [36] } & 12 & 75.0 & 16.2 & 1.3 & & & & & & & 12 & 75.0 & TD & 16.0 & 1.7 & & & & & & \\
\hline & 11 & 63.6 & 24.2 & 5.1 & & & & & & & 11 & 63.6 & $\mathrm{TD}$ & 27.6 & 5.0 & & & & & & \\
\hline Grove \& Lazarus 2007 [37] & 16 & & 9.5 & 1.8 & & & & & & & 14 & & TD & 9.8 & 2.0 & & & & & & \\
\hline Johnston et al. 2002 [10] & 32 & 68.8 & 9.3 & 0.9 & 137.8 & 7.3 & 35.1 & 8.2 & & & 32 & 46.9 & TD & 9.3 & 0.9 & 138.4 & 12 & 35.5 & 13.9 & & \\
\hline Kane \& Barden 2014 [38] & 11 & 81.8 & 11.1 & 2.1 & & & & & & & 11 & 81.8 & TD & 10.9 & 2.5 & & & & & & \\
\hline Przysucha \& Taylor 2004 [41] & 20 & 100.0 & 8.6 & 2.1 & & & & & & & 20 & 100.0 & TD & 8.5 & 2.00 & & & & & & \\
\hline \multirow{2}{*}{ Przysucha et al. 2008 [42] } & 9 & 100.0 & 7 & 0.9 & 128.1 & 7.9 & & & & & 10 & 100.0 & TD & 6.9 & 0.7 & 125.8 & 9.2 & & & & \\
\hline & 8 & 100.0 & 10.5 & 1.5 & 146.7 & 10.5 & & & & & 9 & 100.0 & TD & 10.7 & 1.2 & 147.4 & 9.1 & & & & \\
\hline Speedtsberg et al. 2017 [43] & 9 & 77.8 & 9.0 & 0.5 & 139.9 & 2.5 & 33.1 & 2.3 & & & 10 & 70.0 & $\mathrm{TD}$ & 9.1 & 0.4 & 141.1 & 3.0 & 33.7 & 1.8 & & \\
\hline Speedtsberg et al. 2018 [44] & 8 & 75.0 & 8.8 & 1.5 & 139.5 & 8.1 & 33.6 & 7.3 & & & 10 & 70.0 & TD & 9.1 & 1.4 & 141.1 & 3.0 & 33.7 & 1.8 & & \\
\hline Tsai et al. 2008 [47] & 64 & 46.9 & 10.1 & 0.3 & & & & & & & 71 & 46.5 & TD & 10.3 & 0.2 & & & & & & \\
\hline Tsai \& Wu 2008 [46] & 60 & 50.0 & 10.1 & 0.3 & & & & & & & 60 & 29 & TD & 10.1 & 0.4 & & & & & & \\
\hline Tsai et al. 2009 [45] & 39 & 59.0 & 9.7 & 0.4 & 137.4 & 6.7 & 36.9 & 11.2 & 19.2 & 4.7 & 39 & 48.3 & TD & 9.6 & 0.2 & 136.4 & 6.2 & 34.7 & 8.4 & 18.5 & 3.8 \\
\hline Tsang et al. 2012 [48] & 33 & 81.8 & 7.8 & 1.4 & 127.7 & 10.7 & 30.1 & 10.7 & 17.9 & 3.5 & 30 & 80.0 & TD & 7.6 & 1.1 & 127.5 & 8.7 & 29.6 & 7.9 & 17.9 & 3.0 \\
\hline Wilmut \& Barnett 2017 [49] & 15 & 60.0 & 25.4 & & & & & & & & 15 & 60.0 & $\mathrm{TD}$ & 23.3 & & & & & & & \\
\hline Wilmut \& Barnett 2017 [49]** & 15 & 73.3 & 14.9 & & & & & & & & 15 & 73.3 & TD & 14.6 & & & & & & & \\
\hline Wilmut et al. $2016[50]^{* * *}$ & 14 & 85.7 & 9.3 & & & & & & & & 14 & 85.7 & $\mathrm{TD}$ & 9.3 & & & & & & & \\
\hline Yam \& Fong 2019 [51] & 48 & 77.0 & 8.0 & 1.1 & 126.8 & 9.9 & 26.0 & 7.2 & 15.9 & 2.8 & 51 & 62.7 & TD & 7.8 & 1.1 & 126.5 & 7.8 & 25.5 & 6.5 & 15.7 & 2.3 \\
\hline TOTAL & 1152 & 72.1 & 10.4 & & & & & & & & 1103 & 67.3 & & 10.4 & & & & & & & \\
\hline
\end{tabular}

Legend: TD: typical development; N: number of participants; SD: standard deviation; *identical samples; **identical samples. 
A. Impairment scores on the balance subscale of the Movement Assessment Battery for Children (MABC)

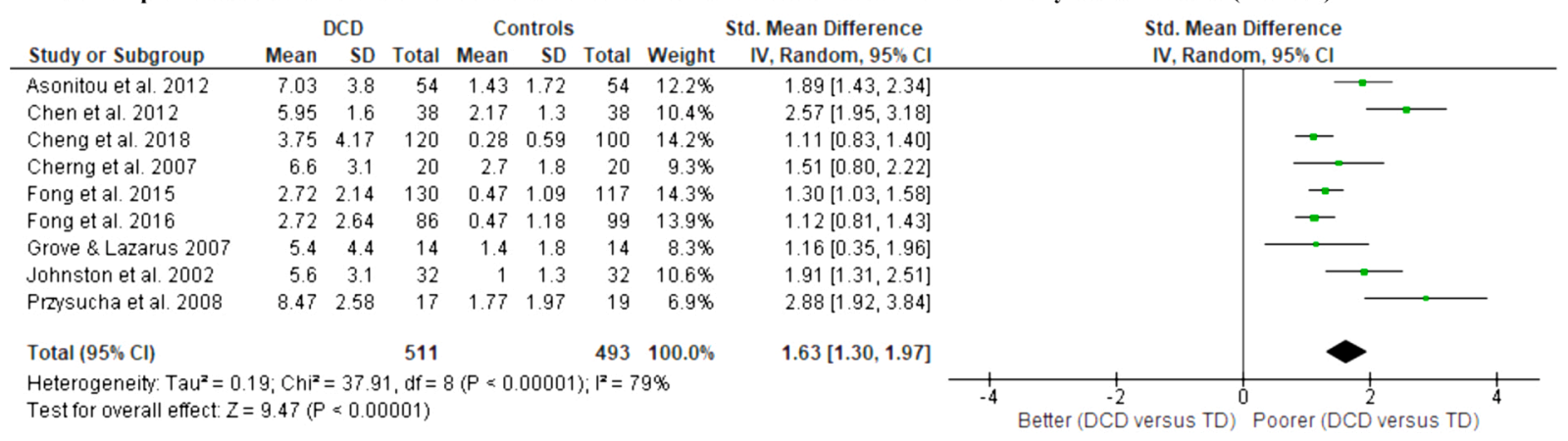

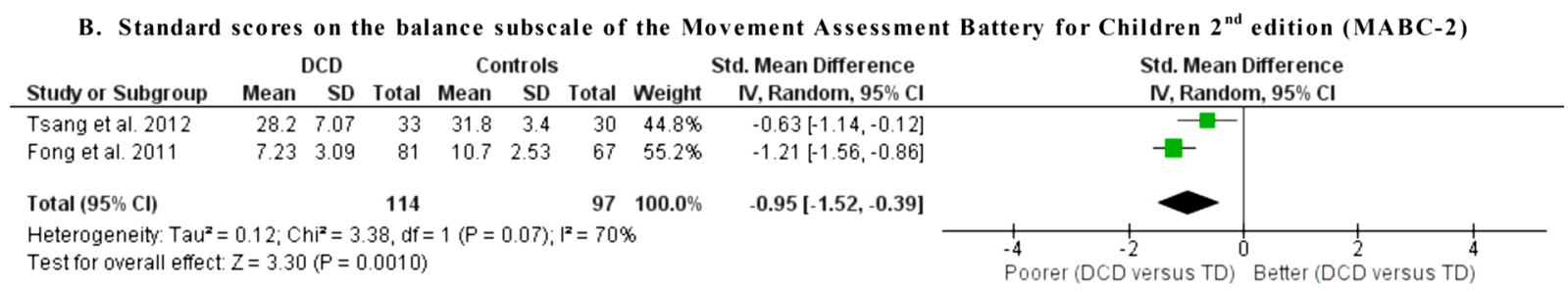

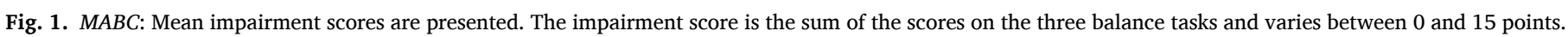

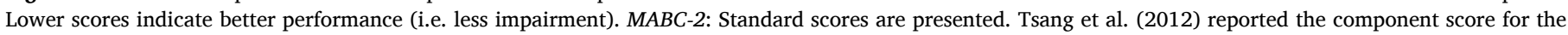

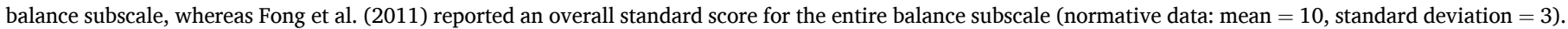
SD: standard deviation; 95\% CI: 95\% confidence interval. Higher scores indicate better performance.

were pooled [31,33,34,37,42,45-47] (Fig. 2). The data were categorized according to the different sensory conditions, analogous with the composition of the sensory orientation test: 1) standing on firm surface with eyes open [31,33,34,41,45,46] (Fig. 2.1), 2) standing on firm surface with eyes closed [31,33,34,41,46,47] (Fig. 2.2), 3) standing on firm surface with a moving visual surround [31,33,34] (Fig. 2.3), 4) standing on a moving platform with eyes open [31,33,34] (Fig. 2.4), 5) standing on a moving platform with eyes closed [31,33,34] (Fig. 2.5), 6) standing on a moving platform with moving visual surround [31,33,34] (Fig. 2.6) and 7) composite scores and sensory ratios [31,33,34,37] (Fig. 2.7).

During natural stance with eyes open (Fig. 2.1) children with DCD have a significantly larger sway area (pooled $\mathrm{SMD}=0.35,95 \% \mathrm{CI}=$ $[0.08 ; 0.62]$ ) $[41,45,47]$, sway path (pooled $\mathrm{SMD}=0.40,95 \% \mathrm{CI}=$ $[0.16 ; 0.63]$ ) $[41,46,47]$ and equilibrium score (pooled SMD $=-0.67,95$ $\% \mathrm{CI}=[-0.96 ;-0.37])[31,34]$, but a similar movement strategy (ankle versus hip) (pooled $\mathrm{SMD}=-0.22,95 \% \mathrm{CI}=[-0.55 ; 0.11]$ ) $[33,34]$ compared to TD peers. A strategy score near 100 indicates a full ankle strategy, whereas a score near 0 indicates a full hip strategy. As shown in Fig. 2.3, similar findings were reported for standing on firm surface with a moving visual surround. During stance with eyes closed (Fig. 2.2) similar results were found as for the eyes open condition, but here also significantly larger strategy scores were seen in TD children compared to their peers with DCD (pooled SMD $=-0.37,95 \% \mathrm{CI}=[-0.70 ;-0.04]$ ) [33, 34], indicating children with TD use more ankle strategy than children with DCD.

In the more challenging conditions, where the support surface moves slightly, the same trend is seen for the equilibrium score and the strategy score as when the children stood on firm surface with eyes closed, but the magnitude of the SDM is larger (Fig. 2.4, 2.5, 2.6). Thus, children with DCD show a larger amount of postural sway and more hip strategy while maintaining the position compared to TD peers. The relative influence of the sensory conditions (Fig. 2.7) was consistently present for the composite score (pooled $\mathrm{SMD}=-0.80,95 \% \mathrm{CI}=[-1.08 ;-0.53]$ ) [31, $34,37]$ and all the sensory ratios: the somatosensory ratio (pooled $\mathrm{SMD}=-0.32, \quad 95 \% \mathrm{CI}=[-0.61 ;-0.03]$ ), the visual ratio (pooled $\mathrm{SMD}=-0.54,95 \% \mathrm{CI}=[-0.78 ;-0.31]$ ) and the vestibular ratio (pooled $\mathrm{SMD}=-0.55$, $95 \% \mathrm{CI}=[-0.89 ;-0.20])[31,33,34]$. However, all pooled results for the equilibrium score, the strategy score and the sensory ratios should be interpreted cautiously as it is unclear whether the children with DCD of these studies belong to the same sample.

Similar trends were seen for other outcome variables for the amount of postural sway when standing with eyes open or closed on firm surface or on foam (Appendix 7). With increasing task-difficulty, e.g. standing on one leg, children with DCD perform consistently poorer then their TD peers $[46,47]$.

\subsubsection{Stability in gait}

In seven studies balance during walking was investigated in four different walking conditions: 1) level walking versus obstacle crossing [28], 2) walking with and without vision [29], walking on treadmill at preferred walking speed $[26,44]$ and 4) walking on high-density foam sports mats $[30,36,49,50]$. None of the available data could be pooled due to differences in tasks and/or outcome variables, or when outcome and task were similar, the same samples were reported in different papers (Appendix 8). The results mainly point towards the absence of consistent differences in step-time and centre of mass parameters between groups during walking.

\section{Discussion}

The aim of this systematic literature review and meta-analysis was to explore balance deficits in individuals with DCD. All included studies compared DCD individuals' performances to those of TD peers. The main findings of the review are that, compared to TD peers, individuals with DCD: 1) perform significantly poorer on balance subscales, derived from generic motor tests (see Fig. 1),2) tend to have more difficulties in their limits of stability and anticipatory postural adjustments (Appendix 5), 3) have significantly more difficulties to maintain a stable standing position in more complex sensory conditions, e.g. standing on a moving platform with eyes closed (Fig. 2, Appendix 7), 4) overall, show similar gait parameters during walking (Appendix 8), and 5) conflicting results were found regarding reactive control (Appendix 6).

Children with DCD present with lower balance subscale scores on the MABC compared to TD peers. Considering the magnitude of the SMD and the proportion of the DCD group which would be below the mean of 
1. Standing on firm surface ground with eyes open

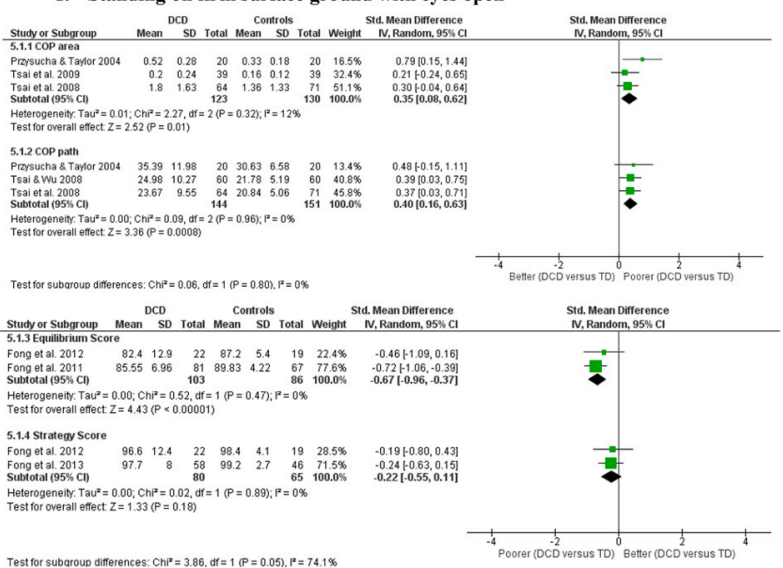

2. Standing on firm surface ground with eyes closed

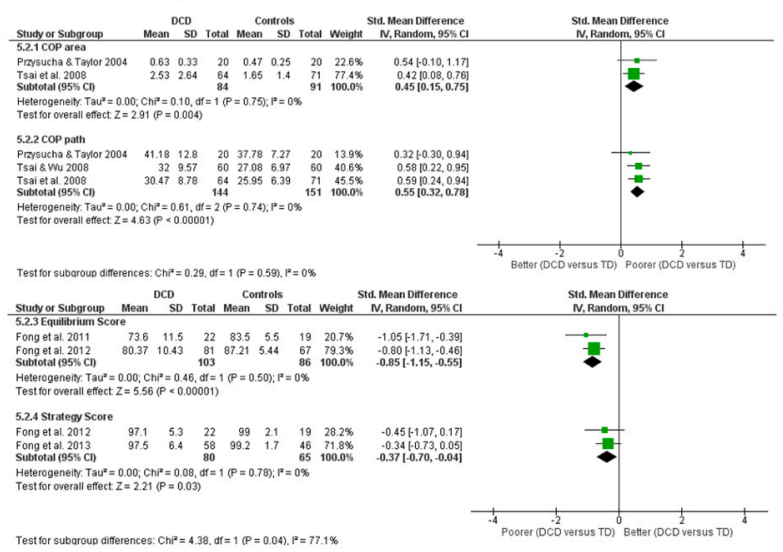

3. Standing on firm surface ground with moving visual surround

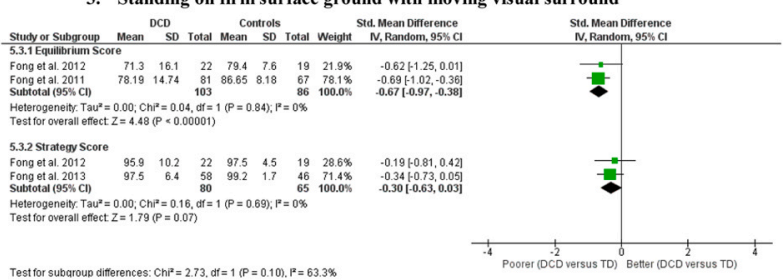

4. Standing on a moving platform with eyes open

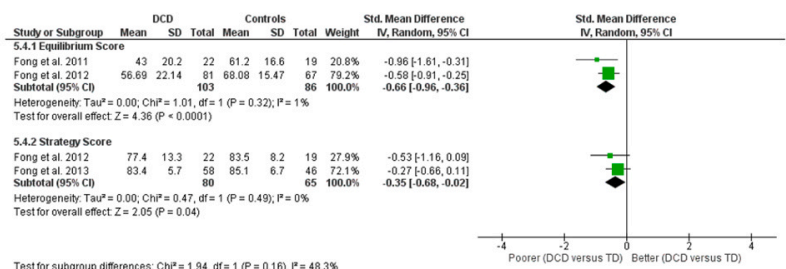

5. Standing on a moving platform with eyes closed

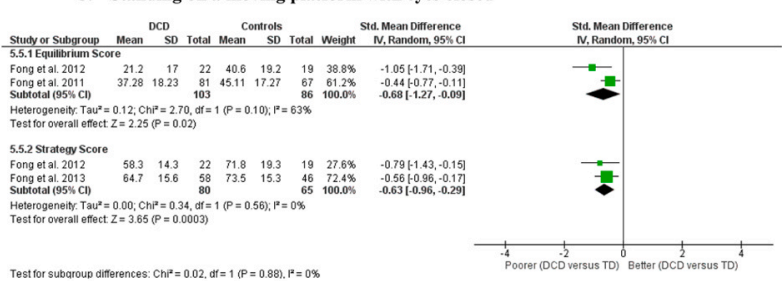

6. Standing on a moving platform with moving visual surround

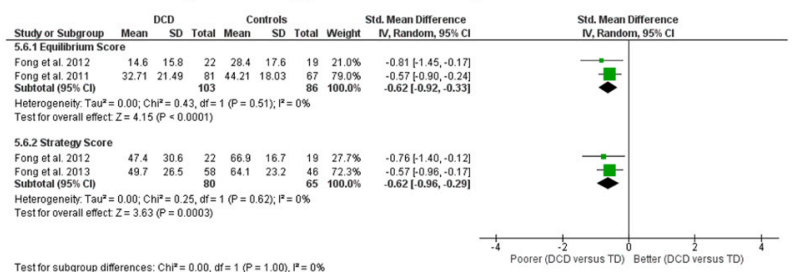

Testfor subarouo dfferences: ChP $=0.00$ dff $=1(P=1.00) P=0 \%$

7. Composite scores and sensory ratios

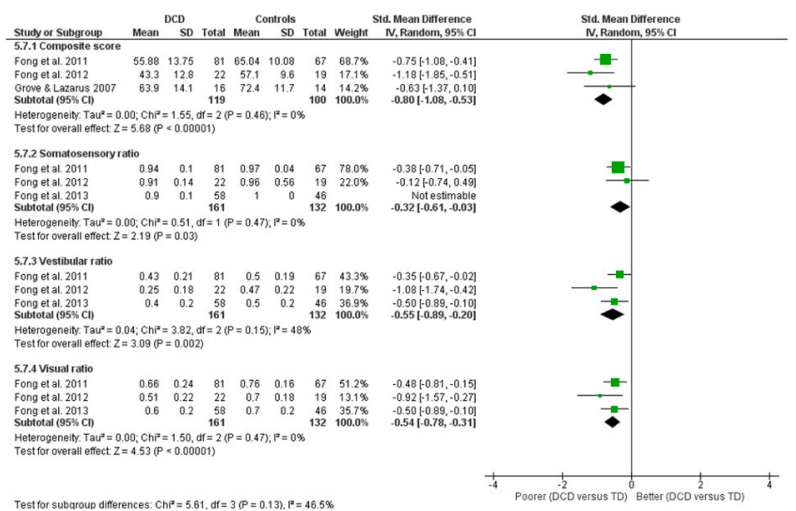

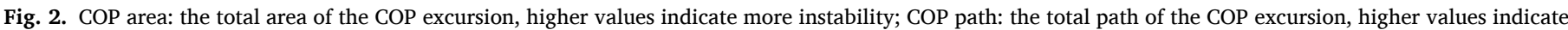

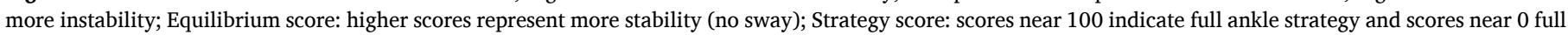

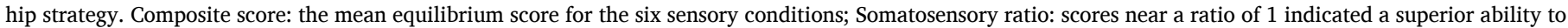

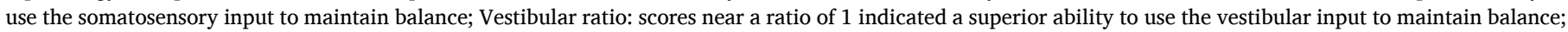

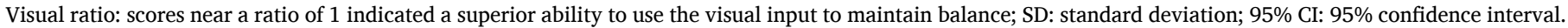


the control group [18], an SMD of 1.6 would indicate that $94.5 \%$ of the DCD group results would be below the TD group mean. Hence, these data suggest that most of the DCD children in the included samples did present with clinically relevant balance problems to some extent (pooled $\mathrm{SMD}=1.63,95 \% \mathrm{CI}=[1.30 ; 1.97])$. Fig. 1 also indicated that heterogeneity in the results was too large. Finding the cause of the heterogeneity is important for making firm conclusions. Heterogeneity can be explained by differences between studies regarding the design, conduct, participants, exposure, outcomes but also the size and direction of the differences [20]. As this review only included studies with the same design, and data of the same outcome measure and metric were pooled, the heterogeneity is probably due to differences in participants across studies inducing imprecision (shown in Fig. 1 by larger $95 \%$ confidence intervals $[10,23,25,37,42])$. The applied criteria for case ascertainment differ largely across studies (Appendix 2). For example, the selection criteria for objectifying the presence of motor performance below expectance regarding chronological age or intelligence vary across studies, e.g. MABC total impairment score below the $5^{\text {th }}$ percentile [21, $23,32,35,42]$ versus at or below the $15^{\text {th }}$ percentile [10,24,25,37]. Also, as shown in Appendix 2, the impact of the motor difficulties on the school- and/or daily activities (diagnostic criterion B) was not always addressed $[10,23,25]$ and when done, different approaches were used. Looking at the characteristics of the included participants, all children showed similar weight, height and BMI for their age (see Table 2). These factors were therefore not considered. The included age groups, however, differed among studies used in the meta-analyses (Fig. 1). Balance is prone to developmental changes [7], but the impairment (Fig. 1A) and standard scores (Fig. 1B) are corrected for age. Based on the reported population characteristics, the differences across studies cannot be explained.

Although the MABC(-2) can be used to screen for a balance deficit, it does not provide any specifics on which balance domains are compromised. Moreover, the balance subscale comprises voluntary movements in static and dynamic situations, indicating it indirectly assesses anticipatory postural adjustments, and static and dynamic balance. Depending on the version of the MABC and the age band, the test also implements a proprioceptive perturbation during one leg stance. Thus, the MABC balance subscale addresses different domains of balance (i.e. anticipatory postural adjustments, and transitions, sensory orientation and stability in gait), but does not assess them separately. Furthermore, this test does not address other domains such as limits of stability, verticality, reactive postural responses and more complex sensory orientation. The latter might be confounding factors for the heterogenous MABC results.

Interestingly, Fig. 2 indicates that sensory orientation is compromised in children with DCD [31,34,37,41,45-47]. In easier conditions (standing on firm surface with eyes open or a moving visual surround), children with DCD present with more sway, but use similar movement strategies, i.e. ankle strategy, than their TD peers. In more difficult conditions (moving platform, Fig. 2.4-2.6), however, the differences become more pronounced and children with DCD start to use more hip strategy than their TD peers, though in both groups the ankle strategy also remains present $[31,33,34]$. This moving platform serves as an unpredictable base of support, which elicits small reactive postural responses to maintain the position as shown by the hip and ankle strategy. Perhaps, the difficulties in these specific sensory organization test conditions (see Fig. 2) might rather be a result of deficient postural reactions than difficulties in sensory integration or reweighting. Indeed, as a result to a forward push, children with DCD also tend to need more time to reach a maximal contraction and a larger peak contraction of the Hamstrings and Gastrocnemius muscles to counteract the perturbation and remain standing [32]. This confirms that children with DCD have trouble showing adequate reactive responses, but this should be interpreted with caution due to the conflicting results regarding the muscle onset latencies following a push versus a moving platform, shown in Appendix $6[24,32]$. Furthermore, the results on the equilibrium and strategy score $[31,33,34]$ should be interpreted cautiously as well. The three studies reporting these data are from the same authors. Based on the description of the sample and the age range it is unclear whether the children are part of the same sample. If this would be the case, the subtotals are no longer valid and the differences between DCD and TD children should be interpreted at the level of the individual studies.

Other authors measured postural sway during one leg stance with eyes open or eyes closed instead of using the sensory organization test paradigm (Appendix 7). When DCD children stand on one leg, they present with more sway than their TD peers both with eyes open and eyes closed $[46,47]$. Although one leg stance was intended in the studies to decrease the base of support and therefore make the condition proprioceptively more difficult, inducing a sensory perturbation [46,47], one leg stance has also been used to investigate anticipatory postural adjustments [38,51] (Appendix 5). During quiet one leg stance, children with DCD have fewer trials with anticipatory onset of the tibialis anterior muscle [38]. Indeed, Kane and colleagues (2012) also showed that children with DCD have less adequate trunk muscle contractions [39]. The anticipatory postural adjustments are not only disturbed during quiet one leg stance, but also when taking stairs or kicking a ball or to prepare for rapid goal-directed arm movements [10,38,39], and therefore seem to be deficient regardless of the task at hand. It could therefore be that the sensory problems by the children with DCD exhibited in the more difficult tasks are also influenced by their deficient anticipatory control.

Thus, both reactive and anticipatory balance mechanisms seem to be disturbed in children with DCD compared to TD peers. The deficiency in these mechanisms can be related to the internal modelling deficit in children with DCD [1]. The anticipatory postural adjustments relate to the extent to which a motor plan is built up and thus relates to both experience and learning. In literature, DCD is often described as a motor learning disorder $[1,63]$, which explains the inefficient anticipatory postural adjustments and the associated difficulties in executing voluntary movements that require a large amount of balance control. Next to the motor plan, constant online monitoring of the movement execution is performed through the sensory input received from the body and environment. By comparing the online input to the existing motor plan in the cerebellum, errors can be adjusted for. However, the feedback-based control is slower compared to the predictive control [1]. In the easier situations, such as exploring the limits of stability in anterior and lateral direction (Appendix 4) or during stance on stable ground with eyes open (Appendix 7), children with DCD are able to adequately adjust for the errors using this slower feedback-based control (Appendix 4, 7), but not in the more difficult tasks that required more anticipatory control as well as more complex sensory integration (Appendix 5, 6 and 7). This is in line with the internal modelling deficit hypothesis for DCD [1]. The anticipatory postural adjustment deficiencies also seem to be direction-specific. All investigated tasks required limb movements in the anterior direction, i.e. arm elevation [10], lifting a leg, kicking a ball, taking stairs [38], Y-balance in the anterior direction [51], requiring control over centre of mass in the opposite direction. Indeed, children with DCD seem to have limited limits of stability in the backward direction [5]. However, whether the reduced backward stability limits are a result of deficient anticipatory postural adjustments or the increasing difficulty level of the task at hand (swaying anteriorly as far as possible is easier than backward) still needs to be determined.

In general, whether the selective motor control through anticipatory postural adjustments, sensory integration processing and/or limits of stability are affected and how they influence one another in children with DCD needs to be determined in future research. To disentangle the origin of the balance deficits these children experience, functional brain imaging (e.g. functional near-infrared spectroscopy) during balance tasks is required.

This review clearly shows that a more comprehensive approach is necessary to obtain a better understanding of which balance domains are 
affected in children with DCD and whether they are interrelated. Although children with DCD seem to be at risk for deficiencies in several balance domains, these results are merely a compilation of individual studies, all investigating a different balance domain. Future research on performances in the different balance domains in these children could be useful to explain the heterogeneity in children with DCD, endorsing the need for subclassification based on a balance profile [6]. Secondly, it could disentangle whether the different domains are interrelated and provide clear implications for their assessment. Finally, longitudinal follow-up of performances in these balance domains in children with DCD could provide valuable information about its developmental course. Even though none of the included studies had a longitudinal design, which would allow determination of the developmental course of balance control in these children, some studies investigated different age groups in both children with DCD and their TD controls [41,42]. It may be expected that children with DCD perform similarly than younger TD children. However, this developmental delay [42] could not be confirmed. We did, however, find deviating results compared to literature on development of balance control. By the age of six, anticipatory postural adjustments before voluntary arm movements during standing quietly are essentially mature in TD children [7]. Johnston and colleagues (2002) showed that in 8- to 10-year-olds, up to $99 \%$ of the children with DCD had delayed muscle contractions performing a rapid goal-directed arm movement, that were below the mean contraction time of TD peers, of the ipsilateral internal oblique muscles (mean $\mathrm{SMD}=3.18,95 \% \mathrm{CI}=[2.44 ; 3.92])$ and the contralateral rectus abdominis (mean $\mathrm{SMD}=3.25$, $95 \% \mathrm{CI}=[2.50 ; 4.00]$ ) [10]. To determine the developmental course of balance control in children with DCD, longitudinal research is necessary.

Not only insights into the developmental course of balance control in children with DCD are lacking, the extent to which the balance problems transfer into adulthood are underexposed. This information is crucial to determine the disorders' long-term impact on overall functioning and deserves attention in future research.

\subsection{Study strengths and limitations}

When interpreting the results of this first study on different balance aspects in individuals with DCD, some strengths and limitations should be considered. All relevant studies seem to be identified by searching three complementary databases as hand searching did not reveal any additional relevant references. With the current methodology we aimed to perform meta-analyses to assess a common result on pooled data of published studies. As such, published studies that reported numeric values of balance test performances were included. This, however, resulted in the exclusion of 12 studies, which focused on relevant aspects of balance control but did not provide numeric values.

Using the SIGN checklist for assessing methodological quality is a strength of this study. The checklist allows the identification of poorly designed studies and demands to reject them from the review, leaving only studies of at least acceptable quality. All but one [24] of the included studies are of acceptable methodological quality, implicating that the conclusions may change in the light of further studies. Especially since research on each specific balance domain is limited or when several studies were available, they all used different tests and/or (types of) outcomes, it is likely that conclusions might change. The risk of bias assessment revealed that most studies might have been exposed to selection bias as shown by the lacking reporting on percentage of participating cases and controls, as well as comparisons between participants and non-participants. Whether outcome bias occurred in the included studies is unclear as this was poorly reported in the majority of the studies.

The applied tests and outcome measures were very diverse, complicating comparison between studies. Especially for the sensory orientation domain and the stability in gait domain, several different parameters were used to investigate differences in performances between groups. The MABC(-2) balance subscale results showed that the included TD children outperformed their DCD peers. These are measures at activity level, in contrast to the outcome measures used to describe performances in the balance domains, that are situated at function level. Children with DCD are known for their limitations in daily activities. Perhaps if the balance domains would be assessed with an outcome measure at activity level such as the Kids BESTest [64], currently being psychometrically assessed in children with cerebral palsy [14], similar magnitude in differences between children with DCD and their TD peers might be obtained as for the $\operatorname{MABC}(-2)$ balance subscales. Such an approach therefore deserves attention in future research.

Although the conceptual framework by Horak et al. (2009) provides a broad overview of different components of balance control and the degree to which they have been investigated in children with DCD, this framework comprises several - still - hypothetical assumptions on posture and postural control. Even though agreement exists that postural control is not one system that merely builds on equilibrium reflexes, its neural basis has not yet been unravelled [65]. For example, the neural circuits used to establish automatic postural reactions, that are seen as a response to external perturbations, remain to be determined. These reactions are assumed to be established through short, medium and long proprioceptive feedback loops, based on empirical studies in patients with sensory neuropathy, multiple sclerosis, Parkinson's disease and cerebellar ataxia [8]. The short and medium latency reactions likely depend on spinal cord and brainstem circuits, whereas the Supplemental Motor Area is thought to influence the release and timing of the long latency component of postural reactions [66]. A recent systematic review and meta-analysis in healthy adults has shown that the cerebellum and Supplemental Motor Area are activated during simulated stance tasks with surface translation or visual field motion [65]. The activation of the cerebellum likely reflects the sensory processing that is needed to ensure the response adequacy [65], whereas activation of the Supplemental Motor Area seems to confirm its influential role. Furthermore, the cerebellum is also related to the automatization of posture and movement, and has therefore been suggested to play a crucial role in the motor learning deficit in children with DCD. To address automatization, the dual-task paradigm can be applied, e.g. a comparison between a postural and a suprapostural task [11]. The framework used in this study does not account for cognitive aspects of postural control. Although its importance is recognized [8], this is a limitation and should be addressed in future research. Nevertheless, new insights into brain activity while actually performing (supra)postural tasks are needed to understand the neural basis of balance control and will thereby also provide clarity about whether its concept is covered by this theoretical model.

Finally, this review has strongly focused on well-known outcome measures such as the muscle onset latencies or spatial centre of pressure outcomes. However, it should be noted that alternative measures have been proposed recently but these have not yet found their way to the DCD community. For example, Haddad et al. (2010) proposed the use of postural time-to-contact to provide insights into balance during suprapostural tasks [12]. Future work on balance in DCD could benefit from incorporating these new measures with ecological tasks.

\section{Conclusion}

In summary, different balance domains may be affected in children with DCD. However, the magnitude of the difference in performance between DCD and TD children seems to depend upon both the applied test and outcome variable. None of the existing studies investigated the entire construct of balance within one group, making it difficult to determine whether the test and outcome are causing the diverging results, or that the heterogeneity of the DCD disorder is accountable for these differences. Current knowledge suggests that children with DCD have deficient anticipatory control and sensory orientation, that becomes more pronounced when tasks become more difficult. More 
detailed insights into whether different balance domains are compromised can help us understand the nature of the heterogeneity of DCD. This may then provide a rationale for subclassifying the children, ultimately to enhance targeted and individualized task-oriented training.

\section{Declaration of Competing Interest}

The authors report no declarations of interest.

\section{Appendix A. Supplementary data}

Supplementary material related to this article can be found, in the online version, at doi:https://doi.org/10.1016/j.gaitpost.2020.10.009.

\section{References}

[1] R. Blank, A.L. Barnett, J. Cairney, D. Green, A. Kirby, H. Polatajko, et al., International clinical practice recommendations on the definition, diagnosis, assessment, intervention, and psychosocial aspects of developmental coordination disorder, Dev. Med. Child Neurol. 61 (3) (2019) 242-285.

[2] APA, Diagnostic and Statistical Manual of Mental Disorders American Psychiatric Association Washington, DC, 2013

[3] D.A. Sugden, M.E. Chambers, Stability and change in children with developmental coordination disorder, Child Care Health Dev. 33 (5) (2007) 520-528.

[4] R.H. Geuze, Postural control in children with developmental coordination disorder, Neural Plast. 12 (2-3) (2005) 183-196, discussion 263-272.

[5] S.S. Fong, S.S. Ng, L.M. Chung, W.Y. Ki, L.P. Chow, D.J. Macfarlane, Directionspecific impairment of stability limits and falls in children with developmental coordination disorder: implications for rehabilitation, Gait Posture 43 (2016) 60-64.

[6] J.J. Macnab, L.T. Miller, H.J. Polatajko, The search for subtypes of DCD: is cluster analysis the answer? Hum. Mov. Sci. 20 (1-2) (2001) 49-72.

[7] W.M. Shumway-Cook A, Motor Control: Translating Research Into Clinical Practice, Wolters Kluwer Health/Lippincott Williams \& Wilkins, Philadelphia, 2012.

[8] F.B. Horak, D.M. Wrisley, J. Frank, The Balance Evaluation Systems Test (BESTest) to differentiate balance deficits, Phys. Ther. 89 (5) (2009) 484-498.

[9] K.M. Sibley, M.K. Beauchamp, K. Van Ooteghem, M. Paterson, K.D. Wittmeier, Components of standing postural control evaluated in pediatric balance measures: a scoping review, Arch. Phys. Med. Rehabil. 98 (10) (2017), 2066-2078.e4.

[10] L.M. Johnston, Y.R. Burns, S.G. Brauer, C.A. Richardson, Differences in postural control and movement performance during goal directed reaching in children with developmental coordination disorder, Hum. Mov. Sci. 21 (5-6) (2002) 583-601.

[11] J.M. Haddad, S. Rietdyk, L.J. Claxton, J.E. Huber, Task-dependent postural control throughout the lifespan, Exerc. Sport Sci. Rev. 41 (2) (2013) 123-132.

[12] J.M. Haddad, J.H. Ryu, J.M. Seaman, K.C. Ponto, Time-to-contact measures capture modulations in posture based on the precision demands of a manual task, Gait Posture 32 (4) (2010) 592-596.

[13] S. Di Carlo, E. Bravini, S. Vercelli, G. Massazza, G. Ferriero, The Mini-BESTest: a review of psychometric properties, Int. J. Rehab. Res. Internationale Zeitschrift fur Rehabilitationsforschung. Revue internationale de recherches de readaptation 39 (2) (2016) 97-105.

[14] R. Dewar, A.P. Claus, K. Tucker, R.S. Ware, L.M. Johnston, Reproducibility of the Kids-BESTest and the Kids-Mini-BESTest for children with cerebral palsy, Arch. Phys. Med. Rehabil. 100 (4) (2019) 695-702.

[15] D. Moher, A. Liberati, J. Tetzlaff, D.G. Altman, Preferred reporting items for systematic reviews and meta-analyses: the PRISMA statement, BMJ 339 (2009) b2535.

[16] Scottish Intercollegiate Guidelines Network SIGN, 2020 https://www.sign.ac. uk/checklists-and-notes.html (Accessed).

[17] J.M. Hootman, J.B. Driban, M.R. Sitler, K.P. Harris, N.M. Cattano, Reliability and validity of three quality rating instruments for systematic reviews of observational studies, Res. Synth. Methods 2 (2) (2011) 110-118.

[18] D.K. Lee, Alternatives to P value: confidence interval and effect size, Korean J. Anesthesiol. 69 (6) (2016) 555-562.

[19] S. Hillier, G. Inglis-Jassiem, Rehabilitation for community-dwelling people with stroke: home or centre based? A systematic review, Int. J. Stroke 5 (3) (2010) $178-186$.

[20] Jh. Higgins, SG, Quantifying heterogeneity in a meta-analysis, Statist. Med. (21) (2002) 1539-1558.

[21] K. Asonitou, D. Koutsouki, T. Kourtessis, S. Charitou, Motor and cognitive performance differences between children with and without developmental coordination disorder (DCD), Res. Dev. Disabil. 33 (4) (2012) 996-1005.

[22] F.C. Chen, C.L. Tsai, Light finger contact concurrently reduces postural sway and enhances signal detection performance in children with developmental coordination disorder, Gait Posture 45 (2016) 193-197.

[23] F.C. Chen, C.L. Tsai, T.A. Stoffregen, C.H. Chang, M.G. Wade, Postural adaptations to a suprapostural memory task among children with and without developmental coordination disorder, Dev. Med. Child Neurol. 54 (2) (2012) 155-159.

[24] Y.T.Y. Cheng, W.W.N. Tsang, C.M. Schooling, S.S.M. Fong, Reactive balance performance and neuromuscular and cognitive responses to unpredictable balance perturbations in children with developmental coordination disorder, Gait Posture 62 (2018) 20-26.

[25] R.J. Cherng, Y.W. Hsu, Y.J. Chen, J.Y. Chen, Standing balance of children with developmental coordination disorder under altered sensory conditions, Hum. Mov. Sci. 26 (6) (2007) 913-926.

[26] F.J. Deconinck, D. De Clercq, G.J. Savelsbergh, R. Van Coster, A. Oostra, G. Dewitte, et al., Differences in gait between children with and without developmental coordination disorder, Motor Control 10 (2) (2006) 125-142.

[27] F.J. Deconinck, D. De Clercq, R. Van Coster, A. Ooostra, G. Dewitte, G. J. Savelsbergh, et al., Sensory contributions to balance in boys with developmental coordination disorder, Adapt. Phys. Activ. Q. 25 (1) (2008) 17-35.

[28] F.J. Deconinck, G.J. Savelsbergh, D. De Clercq, M. Lenoir, Balance problems during obstacle crossing in children with developmental coordination disorder, Gait Posture 32 (3) (2010) 327-331.

[29] F.J.A. Deconinck, D. De Clercq, G.J.P. Savelsbergh, R. Van Coster, A. Oostra, G. Dewitte, et al., Visual contribution to walking in children with Developmental Coordination Disorder, Child Care Health Dev. 32 (6) (2006) 711-722.

[30] W. Du, K. Wilmut, A.L. Barnett, Level walking in adults with and without developmental coordination disorder: an analysis of movement variability, Hum. Mov. Sci. 43 (2015) 9-14.

[31] S.S. Fong, V.Y. Lee, M.Y. Pang, Sensory organization of balance control in children with developmental coordination disorder, Res. Dev. Disabil. 32 (6) (2011) 2376-2382.

[32] S.S. Fong, S.S. Ng, X. Guo, Y. Wang, R.C. Chung, G. Stat, et al., Deficits in lower limb muscle reflex contraction latency and peak force are associated with impairments in postural control and gross motor skills of children with developmental coordination disorder: a cross-sectional study, Medicine (Baltimore) 94 (41) (2015) e1785.

[33] S.S. Fong, S.S. Ng, B.P. Yiu, Slowed muscle force production and sensory organization deficits contribute to altered postural control strategies in children with developmental coordination disorder, Res. Dev. Disabil. 34 (9) (2013) 3040-3048.

[34] S.S. Fong, W.W. Tsang, G.Y. Ng, Altered postural control strategies and sensory organization in children with developmental coordination disorder, Hum. Mov. Sci. 31 (5) (2012) 1317-1327.

[35] S.S.M. Fong, J.W.Y. Chung, Y.T.Y. Cheng, T.T.T. Yam, H.C. Chiu, D.Y.T. Fong, et al., Attention during functional tasks is associated with motor performance in children with developmental coordination disorder: a cross-sectional study, Medicine 95 (37) (2016).

[36] J. Gentle, A.L. Barnett, K. Wilmut, Adaptations to walking on an uneven terrain for individuals with and without developmental coordination disorder, Hum. Mov. Sci. 49 (2016) 346-353.

[37] C.R. Grove, J.A. Lazarus, Impaired re-weighting of sensory feedback for maintenance of postural control in children with developmental coordination disorder, Hum. Mov. Sci. 26 (3) (2007) 457-476.

[38] K. Kane, J. Barden, Frequency of anticipatory trunk muscle onsets in children with and without developmental coordination disorder, Phys. Occup. Ther. Pediatr. 34 (1) (2014) 75-89.

[39] K. Kane, J. Barden, Contributions of trunk muscles to anticipatory postural control in children with and without developmental coordination disorder, Hum. Mov. Sci, 31 (3) (2012) 707-720.

[40] H.L. Miller, P.M. Caçola, G.M. Sherrod, R.M. Patterson, N.L. Bugnariu, Children with autism spectrum disorder, developmental coordination disorder, and typical development differ in characteristics of dynamic postural control: a preliminary study, Gait Posture 67 (2019) 9-11.

[41] E.P. Przysucha, M.J. Taylor, Control of stance and developmental coordination disorder: the role of visual information, Adapt. Phys. Act. Q. 21 (1) (2004) 19-33.

[42] E.P. Przysucha, M.J. Taylor, D. Weber, The nature and control of postural adaptations of boys with and without developmental coordination disorder, Adapt. Phys. Act. Q. 25 (1) (2008) 1-16.

[43] M.B. Speedtsberg, S.B. Christensen, K.K. Andersen, J. Bencke, B.R. Jensen, D. J. Curtis, Impaired postural control in children with developmental coordination disorder is related to less efficient central as well as peripheral control, Gait Posture 51 (2017) 1-6.

[44] M.B. Speedtsberg, S.B. Christensen, J. Stenum, T. Kallemose, J. Bencke, D.J. Curtis, et al., Local dynamic stability during treadmill walking can detect children with developmental coordination disorder, Gait Posture 59 (2018) 99-103.

[45] C.L. Tsai, C.Y. Pan, R.J. Cherng, S.K. Wu, Dual-task study of cognitive and postural interference: a preliminary investigation of the automatization deficit hypothesis of developmental co-ordination disorder, Child Care Health Dev. 35 (4) (2009) 551-560.

[46] C.L. Tsai, S.K. Wu, Relationship of visual perceptual deficit and motor impairment in children with developmental coordination disorder, Percept. Mot. Skills 107 (2) (2008) 457-472.

[47] C.L. Tsai, S.K. Wu, C.H. Huang, Static balance in children with developmental coordination disorder, Hum. Mov. Sci. 27 (1) (2008) 142-153.

[48] W.W. Tsang, X. Guo, S.S. Fong, K.K. Mak, M.Y. Pang, Activity participation intensity is associated with skeletal development in pre-pubertal children with developmental coordination disorder, Res. Dev. Disabil. 33 (6) (2012) 1898-1904.

[49] K. Wilmut, A.L. Barnett, When an object appears unexpectedly: anticipatory movement and object circumvention in individuals with and without developmental coordination disorder, Exp. Brain Res. 235 (5) (2017) 1531-1540.

[50] K. Wilmut, W. Du, A.L. Barnett, Gait patterns in children with developmental coordination disorder, Exp. Brain Res. 234 (6) (2016) 1747-1755.

[51] T.T.T. Yam, S.S.M. Fong, Y-balance test performance and leg muscle activations of children with developmental coordination disorder, J. Mot. Behav. 51 (4) (2019) 385-393. 
[52] W.N. Bair, J.A. Barela, J. Whitall, J.J. Jeka, J.E. Clark, Children with developmental coordination disorder benefit from using vision in combination with touch information for quiet standing, Gait Posture 34 (2) (2011) 183-190.

[53] W.N. Bair, T. Kiemel, J.J. Jeka, J.E. Clark, Development of multisensory reweighting is impaired for quiet stance control in children with developmental coordination disorder (DCD), PLoS One 7 (7) (2012).

[54] F.C. Chen, C.L. Tsai, T.A. Stoffregen, M.G. Wade, Postural responses to a suprapostural visual task among children with and without developmental coordination disorder, Res. Dev. Disabil. 32 (5) (2011) 1948-1956.

[55] F.C. Chen, C.L. Tsai, S.K. Wu, Postural sway and perception of affordances in children at risk for developmental coordination disorder, Exp. Brain Res. 232 (7) (2014) 2155-2165.

[56] R.H. Geuze, Static balance and developmental coordination disorder, Hum. Mov. Sci. 22 (4-5) (2003) 527-548.

[57] M. Jover, C. Schmitz, L. Centelles, B. Chabrol, C. Assaiante, Anticipatory postural adjustments in a bimanual load-lifting task in children with developmental coordination disorder, Dev. Med. Child Neurol. 52 (9) (2010) 850-855.

[58] A. Jucaite, E. Fernell, H. Forssberg, M. Hadders-Algra, Deficient coordination of associated postural adjustments during a lifting task in children with neurodevelopmental disorders, Dev. Med. Child Neurol. 45 (11) (2003) 731-742.

[59] Y. Laufer, T. Ashkenazi, N. Josman, The effects of a concurrent cognitive task on the postural control of young children with and without developmental coordination disorder, Gait Posture 27 (2) (2008) 347-351.
[60] M.O. Wagner, J. Kastner, F. Petermann, D. Jekauc, A. Worth, K. Bos, The impact of obesity on developmental coordination disorder in adolescence, Res. Dev. Disabil. 32 (5) (2011) 1970-1976.

[61] H.G. Williams, A. Castro, Timing and force characteristics of muscle activity: postural control in children with and without developmental coordination disorders, Aust. Educ. Dev. Psychol. 14 (1) (1997) 43-54.

[62] U. Ganapathy Sankar, R. Monisha, Assessment of balance in children with developmental coordination disorder in Indian context, Indian J. Public Health Res. Dev. 10 (7) (2019) 67-70.

[63] P.H. Wilson, B. Smits-Engelsman, K. Caeyenberghs, B. Steenbergen, D. Sugden, J. Clark, et al., Cognitive and neuroimaging findings in developmental coordination disorder: new insights from a systematic review of recent research, Dev. Med. Child Neurol. 59 (11) (2017) 1117-1129.

[64] R. Dewar, A.P. Claus, K. Tucker, R. Ware, L.M. Johnston, Reproducibility of the balance evaluation systems test (BESTest) and the Mini-BESTest in school-aged children, Gait Posture 55 (2017) 68-74.

[65] B.W. Dijkstra, E.M.J. Bekkers, M. Gilat, V. de Rond, R.M. Hardwick, A. Nieuwboer, Functional neuroimaging of human postural control: a systematic review with meta-analysis, Neurosci. Biobehav. Rev. 115 (2020) 351-362.

[66] J.V. Jacobs, F.B. Horak, Cortical control of postural responses, J. Neural Transm. (Vienna) 114 (10) (2007) 1339-1348. 